\title{
Apresentação/Presentation
}

\section{Biografia e Sociedade}

\author{
Biography and society
}

A oposição entre indivíduo e sociedade, ou ainda, entre sujeito e estrutura, remonta discussões teóricas e metodológicas bastante iniciais no campo das Ciências Sociais. Proveniente de um processo de legitimação contínuo e progressivo, a Sociologia, em especial, teve na diferenciação das ciências biológicas e seus métodos um primeiro desafio. Um segundo desafio se caracterizou pela formulação de um objeto próprio e, de forma ainda mais pungente, pela busca por formas adequadas para conhecer este objeto. Assim, na medida em que observamos os desdobramentos da história da disciplina, faz-se evidente que a polarização entre teorias de micro e macro alcance é parte significativa destas disputas por diferenciação externa e coesão interna, próprias de um transcurso metacientífico crítico.

No contexto Europeu, e em especial na Alemanha, eclodiram contrapropostas ao modelo positivista comtiano, de caráter normativo e evolucionista, simultâneas e posteriores à Segunda Guerra Mundial. Srubar (1984) aponta, em sua genealogia da sociologia fenomenologicamente fundamentada que, entre economistas, psicólogos e historiadores alemães, surgiam questionamentos sobre, primeiramente, a legitimidade de uma disciplina que não tinha um objeto próprio bem definido, bem como sobre a possibilidade de uma teoria social fazer uso de métodos provenientes das ciências naturais. Como consequência, o trajeto percorrido pelos que lideravam, por assim dizer, esta resistência, caracterizou-se pela busca de uma nova fundamentação, um novo objeto e um método próprio para as ciências sociais.

A conjuntura destas transformações constitui-se pela tomada da realidade social enquanto um complexo de interações entre indivíduos: a interação social enquanto elemento sociológico

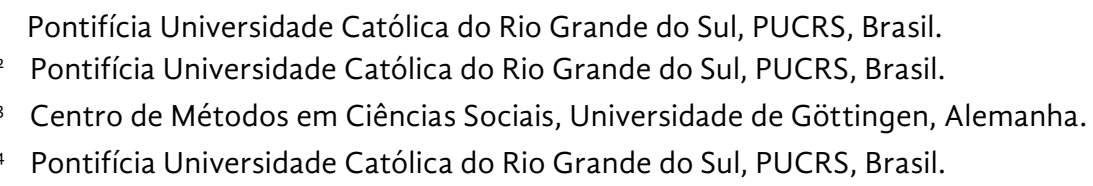


fundamental. Assim, advertia-se que a sociologia deveria passar a investigar os tipos de interação, as ações sociais e seus sentidos, e não mais a sociedade enquanto estrutura em si, desvinculada dos sujeitos em seu fazer cotidiano (SIMMEL, 2006). Entre as vertentes que têm sua gênese neste turning point epistemológico, têm-se, por exemplo, a teoria do conhecimento de Georg Simmel, a sociologia da ação social de Max Weber, o interacionismo simbólico, e a sociologia de orientação fenomenológica, representada principalmente pelas ideias de Alfred Schütz.

É também neste contexto teórico que a pesquisa biográfica, ao menos conforme concebida na vertente sociológica interpretativa, tem sua origem. O relato biográfico, então, passa a ser observado em seu potencial enquanto acesso a construções sociais, e de forma mais marcante, as experiências biográficas em sua natureza interpretada começam a receber crescente enfoque. $\mathrm{Na}$ medida em que busca solução para a dicotomia indivíduo versus sociedade, a sociologia interpretativa e a pesquisa biográfica passam a reconhecer a necessidade de estruturação recíproca entre tempo cronológico e o tempo fenomenológico, e entre mundo da vida e estrutura social. Buscam integrar, assim, a teoria macrossocial e o interesse pelo cotidiano: o contexto não deve ser compreendido como um conjunto de regras dado, mas enquanto estrutura social que é gerada a partir de seu próprio conjunto de condições; a história de vida individual, por sua vez, não deve ser olhada como resultado da organização macrossocial, ou como consequência de uma vida psíquica individual, mas como resultado de atividade subjetiva de construção de sujeitos que interpretam e se apropriam das possibilidades a eles disponíveis (FISCHER-ROSENTHAL, 1995; KOHLI, 1986).

Na sociologia, a utilização de biografias tem início mais significativo nos anos 1920, quando as primeiras tentativas de pesquisa biográfica foram realizadas por sociólogos, antropólogos e psicólogos quase que simultaneamente. A Escola de Chicago foi ímpar no processo de expansão da pesquisa biográfica até a década de 1930. Na década de 1970, a partir da releitura de trabalhos da Escola de Chicago, vê-se emergir novamente o interesse pela pesquisa biográfica interpretativa, em especial na sociologia alemã (ROSENTHAL, 2014). Ainda que uma multiplicidade de métodos tenha sido concebida, extrapolando aquele conjunto em adequação com fundamentações interpretativas ou fenomenológicas, é inegável a importância que este último tem alcançado nas últimas décadas. Tal tradição desponta nos trabalhos brasileiros a partir da produção do sociólogo alemão Fritz Schütze, mas principalmente através da abordagem posteriormente desenvolvida por Gabriele Rosenthal, socióloga alemã que se tornou referência para diversas investigações biográficas em todo o mundo.

O que articula o interesse deste dossiê é, portanto, o uso de narrativas biográficas e de relatos orais como pedras angulares, ou ainda, elementos comuns, aos métodos utilizados pelos autores cujas contribuições aqui se apresentam. Além de difundir e consolidar a pesquisa social biográfica, o dossiê "Biografia e Sociedade" procura apontar diferentes possibilidades do uso de relatos orais, intensificando discussões de nível tanto empírico quanto teórico. Os três artigos que compõem este dossiê demonstram tanto a qualidade dos trabalhos desenvolvidos a partir de abordagens biográficas na academia brasileira, quanto o potencial e o espaço ainda a ser ocupado por pesquisadores vinculados a estas abordagens.

O artigo "As casas de Rafael - a subjetivação do 'morar' e do 'se mudar'”, contribuição de Naida Menezes e Priscila Susin, apresenta os sentidos sociobiográficos atribuídos por Rafael, morador que passou pelo processo de remoção forçada de sua casa em uma das ilhas do Bairro Arquipélago em Porto 
Alegre, Brasil, aos fenômenos do "morar", "habitar" e "se mudar". A partir de uma reconstrução de caso biográfico, as autoras apresentam a importância da compreensão da inter-relação de categorias como "família", "território", "religião" e "trabalho" para a explicação do espaço enquanto "coisa com sentido". Com isso, o artigo promove uma contribuição substancial para a sociologia urbana a partir da perspectiva das experiências daqueles que vivenciam os fenômenos da moradia e da mudança em seu cotidiano.

Já as funções políticas dos discursos sociais, e sua co-constituição em relação às construções biográficas dos sujeitos, é o tema central discutido no artigo "A função política dos discursos sociais e suas implicações sobre a biografia", de Débora Rinaldi e Suliane Cardoso. Utilizando entrevistas semiestruturadas, narrativas biográficas e o método de reconstrução biográfica de caso para a análise das atividades de catadores de resíduos e chefes de gabinete em âmbito legislativo municipal, as autoras reconstroem a instrumentalização de discursos sociais pelos sujeitos para autolegitimar suas práticas cotidianas e para construir uma noção positiva sobre si mesmos. $\mathrm{O}$ artigo propõe uma combinação pouco usual - mas com resultados interessantes - entre a sociologia de orientação fenomenológica de Alfred Schütz e a noção de Pierre Bourdieu acerca da estruturação do mundo social através das práticas. O resultado da análise de três casos evidencia as limitações de uma argumentação essencialmente estruturalista ao demonstrar empiricamente como os sujeitos conferem significado a categorias do mundo social e a sua história familiar para legitimar suas atividades profissionais, seja como catadores de resíduos ou como chefes de gabinete.

Por fim, a contribuição de Karina Schuh Reif e Martín Hernán Di Marco apresenta uma revisão sistemática da literatura sobre as trajetórias biográficas de mulheres e homens autores de crimes ou violências. A revisão indica a vitimização nas trajetórias como um dos fatores que contribuem para a ocorrência dos crimes e a centralidade da socialização do gênero para a compreensão do fenômeno da violência. $O$ artigo demonstra a alta frequência do uso de teorias de gênero e identitárias para o estudo de trajetórias de autores de violências, bem como a ausência de estudos sobre medidas e dispositivos socioeducativos sobre a população feminina, a despeito da frequência mais elevada de estudos sobre essa temática para o universo masculino. Evidencia, portanto, uma lacuna substancial na compreensão e explicação de atos violentos cometidos por mulheres a despeito da ampla difusão das teorias de gênero na área.

Os artigos abrangem, portanto, algumas das possibilidades proporcionadas pelo uso de abordagens biográficas, versando sobre temáticas como violência, desigualdade social, urbanização, relações de poder, de gênero, dentre outros campos temáticos de extrema relevância para as ciências sociais brasileiras. Com isso, esperamos contribuir para a difusão e consolidação de métodos de geração e análise dos dados que façam uso dos preceitos de uma abordagem biográfica, em especial aqueles ancorados em fundamentos interpretativos.

\section{Referências}

BERGER, L. Peter; LUCKMANN, Thomas. A construção social da realidade: tratado de sociologia do conhecimento. Tradução de Floriano de Souza Fernandes. Petrópolis: Vozes, 2004. 
FISCHER-ROSENTHAL, Wolfram. The Problem With Identity: Biography as Solution to Some (Post)-Modernist Dilemmas, 1995. In: MILLER, Robert (org.). Biographical Research Methods. V. II. London: Sage Publications, 2005, p. 212-227. (SAGE Library of Research Methods).

KOHLI, Martin. Social Organization and Subjective Construction of the Life Course, 1986. In: MILLER, Robert (org.). Biographical Research Methods. V. II. London: Sage Publications, 2005, p. 39-63. (SAGE Library of Research Methods).

ROSENTHAL, Gabriele. Pesquisa Social Interpretativa: Uma Introdução. 5. ed. Porto Alegre: EDIPUCRS, 2014.

SRUBAR, Ilja. On the origin of "phenomenological" sociology. Human Studies, Konstanz, v. 7, p. 163-189, 1984. https://doi.org/10.1007/BF02633654

Recebido: 06/12/2019

Aceito: 10/12/2019

\section{Biografia do Autor}

\section{Hermílio Santos}

Professor do Programa de Pós-Graduação e Graduação em Ciências Sociais da PUCRS; ORCID: http://orcid.org/oooo-0002-3207-3330; EMAIL: hermilio@pucrs.br

Instituição: Pontifícia Universidade Católica do Rio Grande do Sul.

Localização: Av. Ipiranga, 6681 -Partenon - Porto Alegre/RS

\section{Naida Menezes}

Doutora em Ciências Sociais (PUCRS); Mestre em História (UFRGS); Pesquisadora no Grupo de Pesquisa em Narrativas Biográficas (PUCRS); Pesquisadora no CAES (Centro de Análises Econômicas e Sociais da PUCRS); ORCID: http://orcid.org/o0oo-0001-8514-6903; EMAIL: contato@naidamenezes.com Instituição: Pontifícia Universidade Católica do Rio Grande do Sul.

Localização: Av. Ipiranga, 6681 -Partenon - Porto Alegre/RS

\section{Lucas Cé Sangalli}

Pesquisador no Centro de Métodos em Ciências Sociais - Pesquisa Social Qualitativa (Methodenzentrum Sozialwissenschaften - Qualitative Sozialforschung), Universidade de Göttingen. Göttingen, Alemanha; ORCID: http://orcid.org/oooo-0002-6209-1767; EMAIL: lucas.sangalli@unigoettingen.de Instituição: Centro de Métodos em Ciências Sociais, Universidade de Göttingen. Localização: Wilhelmsplatz 1, 37073 Göttingen, Alemanha 


\section{Priscila Queirolo Susin}

Psicóloga (PUCRS); Doutora em Ciências Sociais (PUCRS); Mestre em Ciências Sociais (PUCRS); Pesquisadora no CAES (Centro de Análises Econômicas e Sociais da PUCRS); ORCID: http://orcid. org/o000-0002-1957-1634; EMAIL: pri.qsusin@gmail.com Instituição: Pontifícia Universidade Católica do Rio Grande do Sul. Localização: Av. Ipiranga, 6681 -Partenon - Porto Alegre/RS 